\title{
2. MICROSTRUCTURAL ANALYSIS OF DEFORMATION BANDS FROM SITE 860, CHILE MARGIN ${ }^{1}$
}

\author{
E. Louise Rochford, ${ }^{2}$ David J. Prior, ${ }^{2}$ Susan M. Agar, ${ }^{3}$ and Alex Maltman ${ }^{4}$
}

\begin{abstract}
Deformation bands, with good macroscopic and microscopic indicators of shear are the clearest macroscopic manifestation of accretionary deformation from ODPS Site 860. Backscattered electron SEM studies of deformation bands show that these structures are characterized by low porosity, an increase in matrix:grain ratios and grain-size reduction. Locally grain alignment fabrics are observed and some deformation bands show evidence of injection of foreign material and diagenetic changes. Strain magnitudes from space and shape fabrics are small, both inside and outside deformation bands. We propose that deformation bands develop during transient cycles of dilation, shear and fluid flow associated with accretionary deformation.
\end{abstract}

\section{INTRODUCTION}

ODP Site 860 (Behrmann, Lewis, Musgrave, et al., 1992) is located on the seaward flank of a forearc basin above the Chile forearc accretionary wedge (Fig. 1). This section of the forearc lies north of the current site of the Chile Triple Junction and is likely to have evolved without complications related to ridge subduction (Cande and Leslie, 1986). Three structural domains were recognized at Site 860 (Fig. 2): a flat-bedded region from $0-88 \mathrm{mbsf}$, a thrust-stack domain from 88-420 mbsf, and a broken formation from 420-617.8 mbsf. The flat-bedded domain corresponds to $70 \mathrm{~m}$ of Quaternary, slope hemipelagic material; the sections beneath comprise Pliocene strata. It is not clear whether the accretionary wedge underlying the forearc basin was penetrated at Site 860 . Broken formation is characteristic of accretionary complexes but there is no reason why broken formations cannot also develop in forearc basin material.

In the broken formation, the dominant lithology (silty claystone to clayey siltstone) is cut by an intense network of broadly planar, dark zones which we refer to as deformation bands (Behrmann, Lewis, Musgrave, et al., 1992). Deformation bands first appear at 90 mbsf; here they are small, isolated, and relatively insignificant. Below 420 mbsf, deformation bands are larger, more abundant, and more complex in geometry. Also, in this domain, bedding surfaces are modified and there is significant stratal disruption. Detailed analysis of the relative orientations and kinematics of deformation bands within the broken formation defines the patterns of strain they accommodate. Between 520 and 580 mbsf there is a broad, simple shear-zone separating domains of general volumetric deformation (Fig. 3). Within this broad zone, narrower, more intense flat-lying shear zones occur at 520 and 580 mbsf.

Microstructural studies of deformation features in forearcs are important in constraining the conditions of deformation and the interrelationships of deformation, sediment lithification, diagenesis, and fluid flow (Agar et al., 1989; Prior and Behrmann, 1990; Knipe et al., 1991; Byrne et al., 1993; Maltman et al., 1992, 1993). In this paper we describe deformation bands from Site 860 and their implications

\footnotetext{
${ }^{1}$ Lewis, S.D., Behrmann, J.H., Musgrave, R.J., and Cande, S.C. (Eds.), 1995. Proc. $O D P$, Sci. Results, 141: College Station, TX (Ocean Drilling Program).

2 Department of Earth Sciences, University of Liverpool, PO Box 147, Liverpool L69 3BX, United Kingdom. (Rochford's present address: Department of Earth Sciences, Leeds University, Leeds LS2 9JT, United Kingdom.)

${ }^{3}$ Department of Geological Sciences, Northwestern University, Evanston, Illinois 60208, U.S.A.

${ }^{4}$ Institute of Earth Studies, University College of Wales, Llandinam Building, Aberystwyth SY23 3DB, Wales, United Kingdom.
}

for the evolution of the forearc. Structures exert a strong control on fluid movement (Moore et al., 1991; Knipe et al., 1991; Maltman et al., 1993) and are a crucial control on the evolution of forearc complexes, where massive porosity reduction by dewatering is an inevitable consequence of sediment accretion (Bray and Karig, 1985; Moore et al., 1988). At Site 860 there are no perturbations of thermal, geochemical or physical property data across structures to suggest that they are currently active; the observed structures may well be Pliocene in age. However, closer to the toe of the forearc, at Site 859, there are some of the clearest indications that fluids are channelled along active structures (Behrmann, Lewis, Musgrave, et al., 1992).

\section{METHODS}

Specimens were sawn from the core and marked with the up-core orientation. Samples were packed in double heat-sealed bags with a damp sponge in the outer bag to help preserve moisture content. In the laboratory, specimens were trimmed with a precision annular saw and selected chips were vacuum impregnated with epoxy and made into stained and polished thin sections and polished blocks. Samples were examined optically, using fluorescence microscopy, scanning electron microscopy (SEM) and cathodoluminescence (CL) microscopy. A Camscan Series 4 SEM was used to collect backscattered electron (BSE) images with a 4 quadrant solid state detector. A beam current of $20 \mathrm{kV}$ was used with a working distance of $12-25 \mathrm{~mm}$ for most BSE imaging and for qualitative energy dispersive $\mathrm{X}$-ray (EDX) analyses. Some lower kV (generally 10-12 kV) BSE imagery was carried out for improved spatial resolution.

SEM photo-transects were taken across several deformation bands. These were scanned into a Macintosh computer. Grains were delineated using CANVAS 3.0 and the shapes, sizes and positions of these grains quantified using the IMAGE 1.44 image analysis software. The spatial distribution and shape fabrics were analyzed using methods of Fry (1979), computerized by the methods of DePaor (1989), and Wheeler (1984), respectively.

\section{SUMMARY OF MESOSCOPIC OBSERVATIONS}

The sediments sampled at Site 860 comprise diamictites with associated slightly calcareous, fine-grained sediments, with measured porosities of approximately $30 \%-45 \%$.

Above $420 \mathrm{~m}$, the sediments show fine laminations and grading and often appear mottled. Below $420 \mathrm{~m}$, in the broken formation, all bedding surfaces have been obliterated.

Isolated deformation bands occur between 88 and $420 \mathrm{mbsf}$. These are typically $5-10 \mathrm{~cm}$ in length and are generally less than $1 \mathrm{~mm}$ thick, 


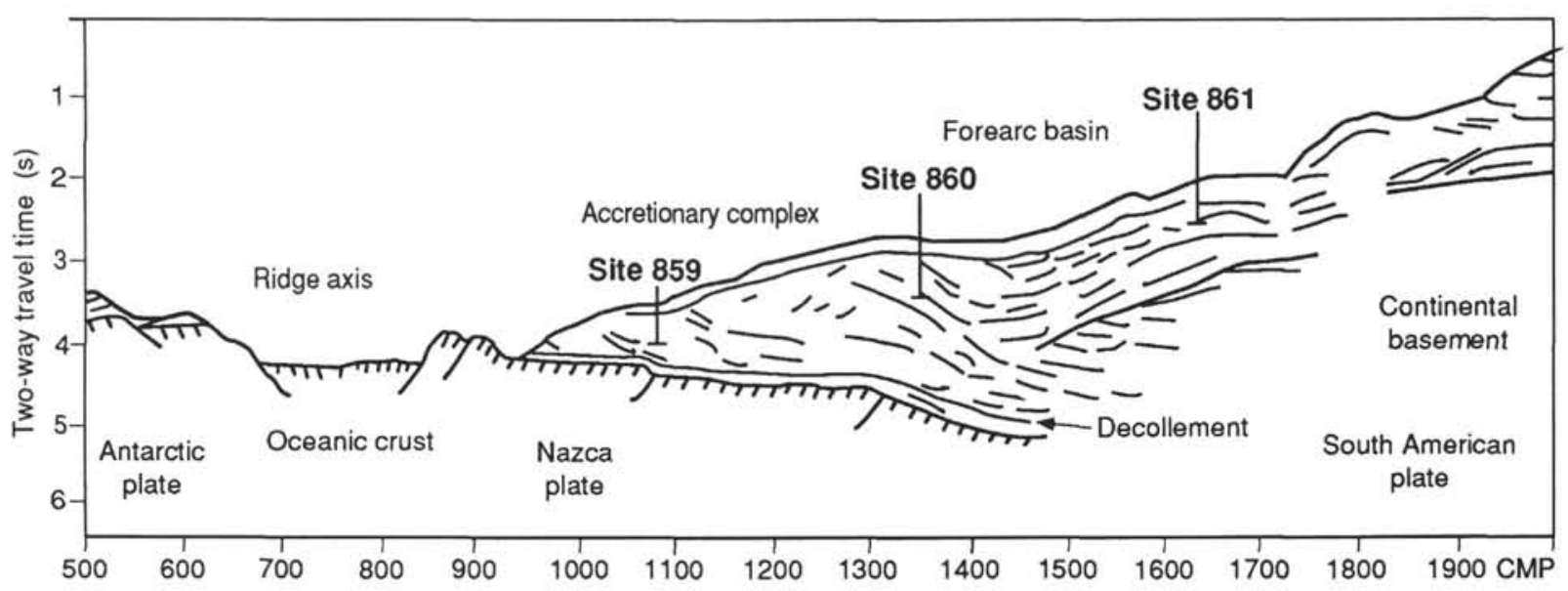

Figure 1. Line-drawing interpretation of seismic Line 745 showing location of Site 860 (from Bangs et al., 1992).

although occasionally they reach $2 \mathrm{~mm}$. In detail these deformation bands comprise an anastomosing network of extremely fine seams. Structural chronologies can be identified within individual corepieces. To some extent, these chronologies can be correlated across larger sections of the core (Behrmann, Lewis, Musgrave, et al., 1992). Most of the deformation bands, where kinematics are constrained in the core, have reverse senses although the senses of many deformation bands remain cryptic (op cit.). More than one phase of reversesense deformation bands are identified. Normal-sense deformation bands, where identified, both predate and postdate reverse sense deformation bands.

\section{MICROSTRUCTURES}

Optical examination shows that the matrices in the deformation band and in the host rock have subtle color differences. In BSE images, deformation bands are characterized by brighter backscatter intensity than the background sediment (PI. 1). Observed deformation bands are between 50 and $2000 \mu \mathrm{m}$ thick. Wide deformation bands commonly occur in subparallel arrays (PI. 1). Microstructural features which characterize deformation bands include porosity variations, shape fabrics, fractures and changes in mineralogy. There is no clear, systematic relationship between the nature of microstructures which characterize any given deformation band and its orientation, though the sampling population in the present study is small.

\section{Porosity Variations}

Contrasting colors indicate slight differences in mineralogy or porosity within deformation bands and the brighter BSE signal within deformation bands must relate to a higher mean atomic number compared to surrounding sediment (Lloyd, 1985). On the grain scale it is clear that a reduction in porosity within deformation bands contributes significantly to the BSE signal contrast (PI. 1, Fig. 2, and Pl. 2, Figs. 1 and 2).

Changes in porosity at deformation band boundaries can be sharp, changing across a distance of less than $20 \mu \mathrm{m}$, as shown in Plate 2, Figures 1,2, and 3, or gradational across several hundred micrometers (PI. 1, Fig. 2). Some wider deformation bands sometimes have one gradational contact and one relatively sharp contact (Pl. 1, Fig. 2). In other cases, both boundaries are relatively discrete (PI. 2, Figs. 4 and 5 ). Porosity in the host sediments is commonly variable, whereas that in wide deformation band tends to be uniform except at gradational contacts (Pl. 1, Fig. 2). Networks of finer deformation bands show complex porosity patterns (Pl. 3).

\section{Fabrics}

Many deformation bands exhibit neither grain alignment nor obvious grain-size variation relative to the adjacent sediment. However, perhaps the most striking feature of almost all the deformation bands from Site 860 is that the most complete alignment of particles parallel to the bands is at their margins. At the resolution of the optical microscope the boundaries of many deformation bands are typified by very abrupt changes in fabric orientation and intensity. Any primary fabric in the host sediment shows no curving into the zones, even where there is independent evidence of shear. The abrupt alignment at the margins occurs even where there is no fabric in the host.

BSE studies show that the grain alignments observed within some deformation bands generally comprise $5-50 \mu \mathrm{m}$ wide zones in which elongate grains, in the $2-20 \mu \mathrm{m}$ size range, are aligned parallel to the deformation band (PI. 2, Figs. 2 and 3). Such alignments are most common at sharp deformation band contacts (Pl. 2, Figs. 2 and 3 ) and where deformation bands are narrow, alignments may pervade the entire thickness of the band. Zones of grain alignment are not laterally persistent and may die out over 100 to $1000 \mu \mathrm{m}$. The host sediment often has grain alignment fabrics which are destroyed or modified within deformation bands. In networks of finer deformation bands complex fabric patterns are observed (PI. 3).

One variety of deformation band appears confined to the upper sediment levels and is unusual in several respects. At about $90 \mathrm{mbsf}$, for example, arrays of narrow deformation bands occur parallel to bedding and its accompanying weak phyllosilicate alignment. Within the bands, the grain alignment is also in this orientation but is much more intense. These zones displace pre-existing deformation bands and show a spatial, and perhaps mechanical, association with high angle kink-like bands (Fig. 4; see Maltman et al., 1993). The phyllosilicate alignment between the bands is weaker than in the host sediment and is orientated at right-angles to the bands (Fig. 4).

\section{Sediment-filled Fractures}

Plate 2, Figure 6, shows a flat-lying, sediment-filled fracture cutting through a Fe-sulfide concretion. Concentrations of Fe-sulfide contained in the infilling material are similar to concentrations in the surrounding sediment. In this case, the infilling sediment appears slightly darker and contains fewer large clasts. The vein filling is clearly not derived from adjacent vein margins and must have been transported along the fracture. In Plate 2, Figures 4 and 5, a coarsegrained deformation band cuts through a clast of fine-grained material, indicating transport of material along the seam for a distance at 
least as great as the width of the clast $(500 \mu \mathrm{m})$. In many other cases, the material within the deformation bands is coarser than the material immediately adjacent to them; the margins of these are not discrete but these may also represent sediment infilling in fractures.

\section{Fe-sulfide Filled Fractures and Fe-sulfide in Deformation Bands}

BSE/EDX studies show that Fe-sulfide is present in the sediments as individual frams, wholly or partially developed framboids and as concentrations of framboids in voids (fossil tests), replacing fossil tests and in concretions (Lindsley-Griffin et al., this volume). Several fractures, dipping zero to $60^{\circ}$, are infilled with framboidal Fe-sulfide ( $\mathrm{Pl}$. 4, Figs. 1 and 2). Calcite and other mineralized veins are not observed at Site 860 . Plate 4 , Figure 1 , shows an $80 \mu \mathrm{m}$ wide, tapering, $\mathrm{Fe}$ sulfide filled crack. Beyond the crack tip there is a concentration of framboidal $\mathrm{Fe}$-sulfide in the matrix in the same orientation as the crack (Pl. 4, Fig. 3). Optical studies show that opaque and semi-opaque finegrained material is concentrated within many deformation bands and BSE images confirm that deformation bands often contain more $\mathrm{Fe}$ sulfide than the surrounding sediment, usually as dispersed frams and more rarely as framboids. The Fe-sulfide contributes to the brighter backscatter of the deformation bands.

\section{Open Fractures}

Although these are found throughout the samples, they commonly occur preferentially along deformation bands. In some cases there are accumulations of Fe-sulfide along the margins of the fractures, indicating that the two features are related.

\section{Mineralogical Variations}

No mineralogical changes are observed between deformation bands and the host sediments, apart from the proportion of Fe-sulfide and modal mineralogical changes associated with porosity variations and sediment infillings. There is a wide variety of clast types and there has been no attempt to quantify variation in clast population inside and outside of deformation bands. The matrix of both the host sediment and the deformation bands contains fine phyllosilicates. EDX analyses do not reveal any changes in matrix phyllosilicate composition across deformation bands. Fluorescence microscopy revealed that there is no concentration of organic matter within the deformation bands. With the exception of a few Fe-sulfide filled cracks and microfossils, the whole rock has only low fluorescence levels.

A sample from Core 48X, for example, shows a conspicuous broad zone of finer grained sediment at right-angles to the subhorizontal bedding. Markers are not displaced by the band, and the lithological difference within the zone gives a resemblance of a sedimentary dike. Other observations suggest, however, that the band is not the result of forceful injection of sediment. The margins of the band are not sharp. A phyllosilicate alignment within the zone is at right-angles rather than parallel to the margins, that is, parallel to the host sediment. In one place, laminations of the host sediment continue across the band (Fig. 5).

\section{Displacements Associated with Deformation Bands}

Macroscopic separations across deformation bands are identified in the core (Behrmann, Lewis, Musgrave, et al., 1992). Direct evidence of displacement across deformation bands is only available where they cut pre-existing features. Microscopically deformation bands characterized by porosity reduction and localized grain-alignment are observed to offset deformational features, such as older deformation bands (PI. 4, Figs. 4 and 5; Fig. 3), and sedimentary features such as fossil tests (Pl. 5, Fig. 1). In contrast, deformation bands characterized microscopically as sediment-filled fractures often show no offsets (PI.

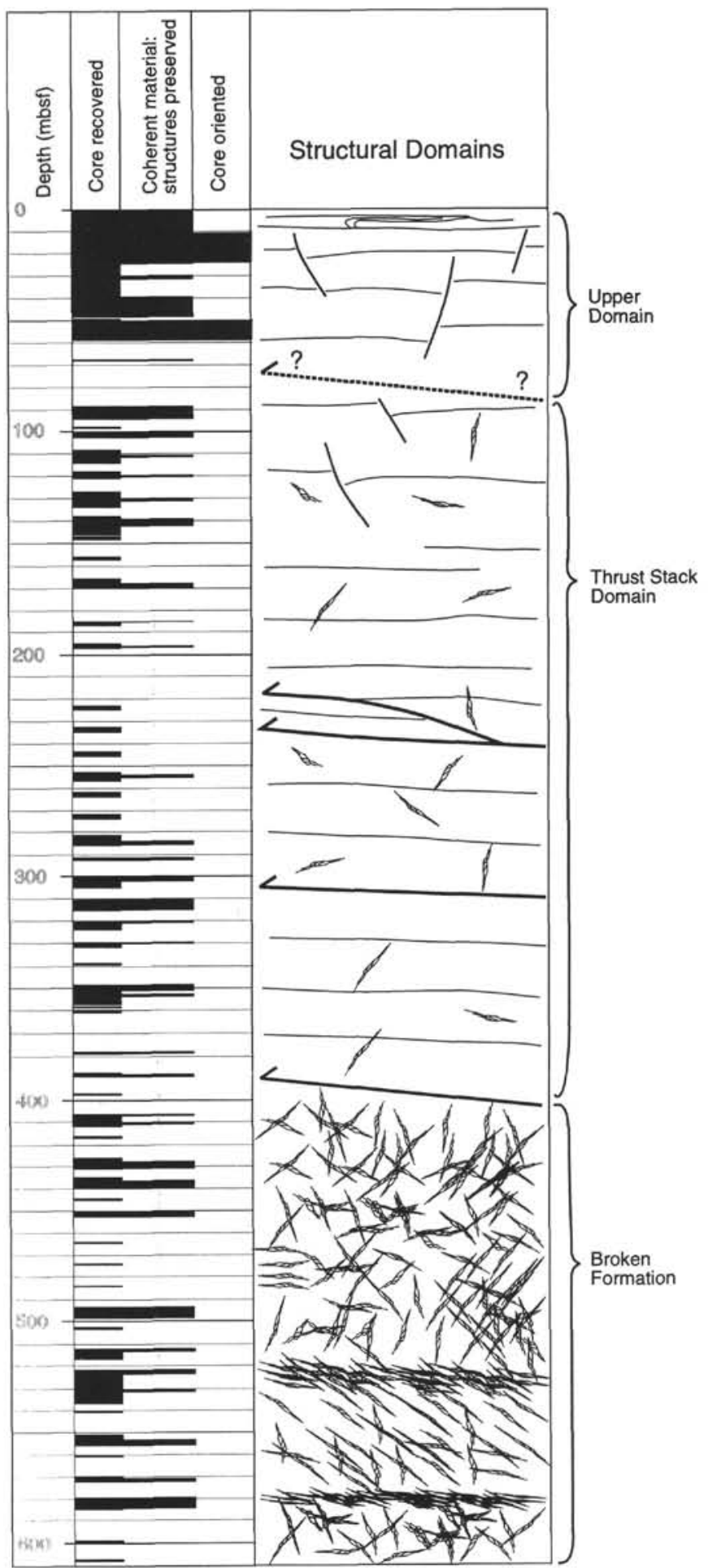

Figure 2. Schematic illustration of major structural features and changes at Site 860 , plotted against depth in the borehole. The first three columns show distribution of sediment recovery, the distribution of material sufficiently coherent to make structural observations, and the distribution of material in which structural measurements could be reoriented into a geographical reference frame. 


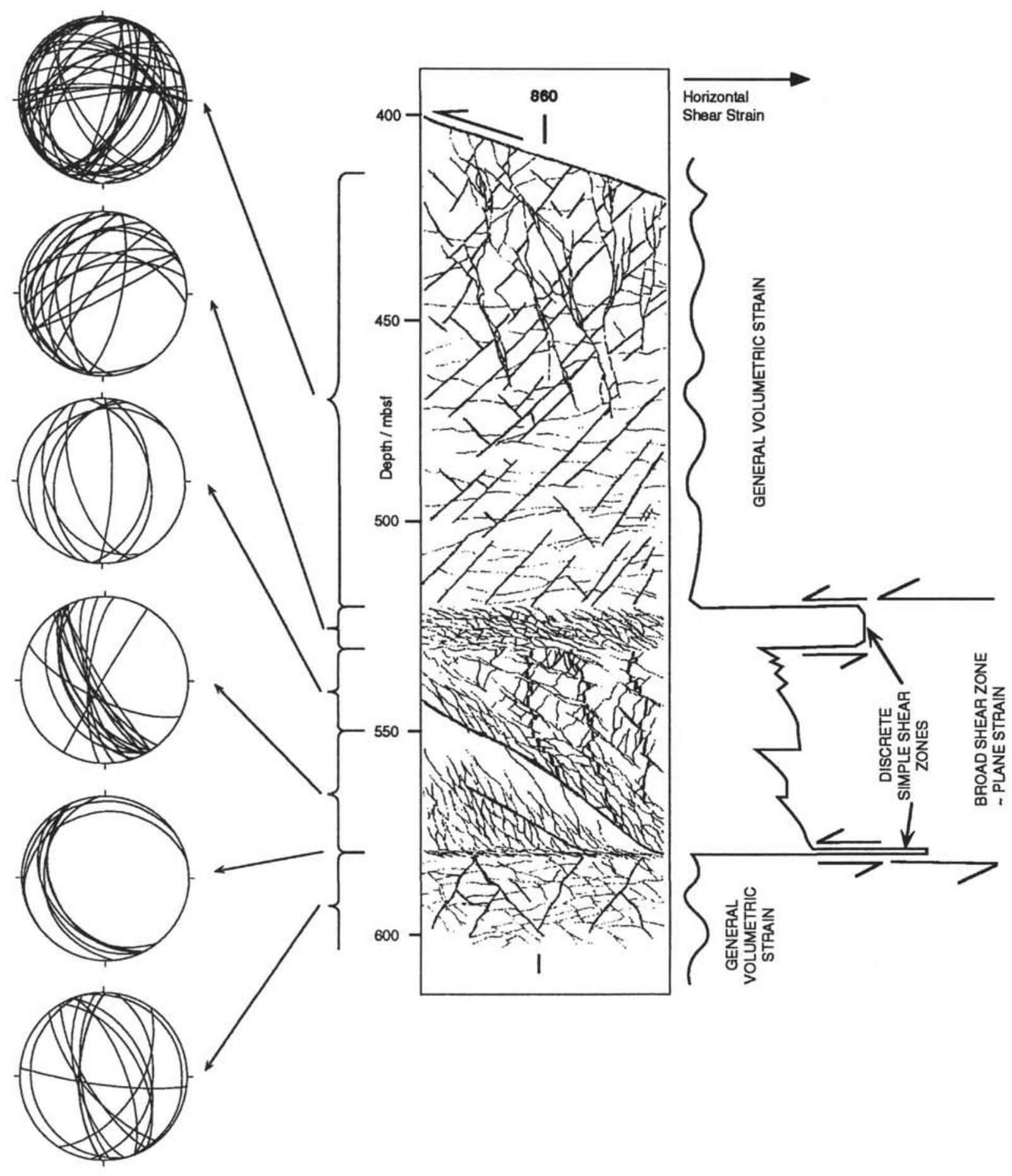

Figure 3. Summary of structural domains within the broken formation. The column is a two dimensional representation of the deformation band geometry illustrated in the stereographic projections (lower hemisphere) on the left. The central dividing line of the column represents the structure at the borehole site. The graph on the right-hand side gives a qualitative estimate of horizontal shear strain associated with the various deformation band geometries and intensities.

2, Figs. 4, 5, and 6). Fe-sulfide filled fractures have not been observed cutting suitable markers and their kinematics are unconstrained.

Deformation bands with constrained separations usually have no microscopic indication of kinematics or strain. There are a few notable exceptions: Plate 4, Figures 5 and 6 , show a biotite clast which is involved in two deformation bands and shows deflections in orienta- tion consistent with shear strain within and parallel to the margins of the deformation bands.

Fe sulfides are dispersed along deformation bands which offset markers comprising significant framboidal Fe-sulfides (PI. 5, Figs. 1 and 3). Individual framboids are not deformed (PI. 5, Fig. 2), even in areas where there are grain fabrics. 


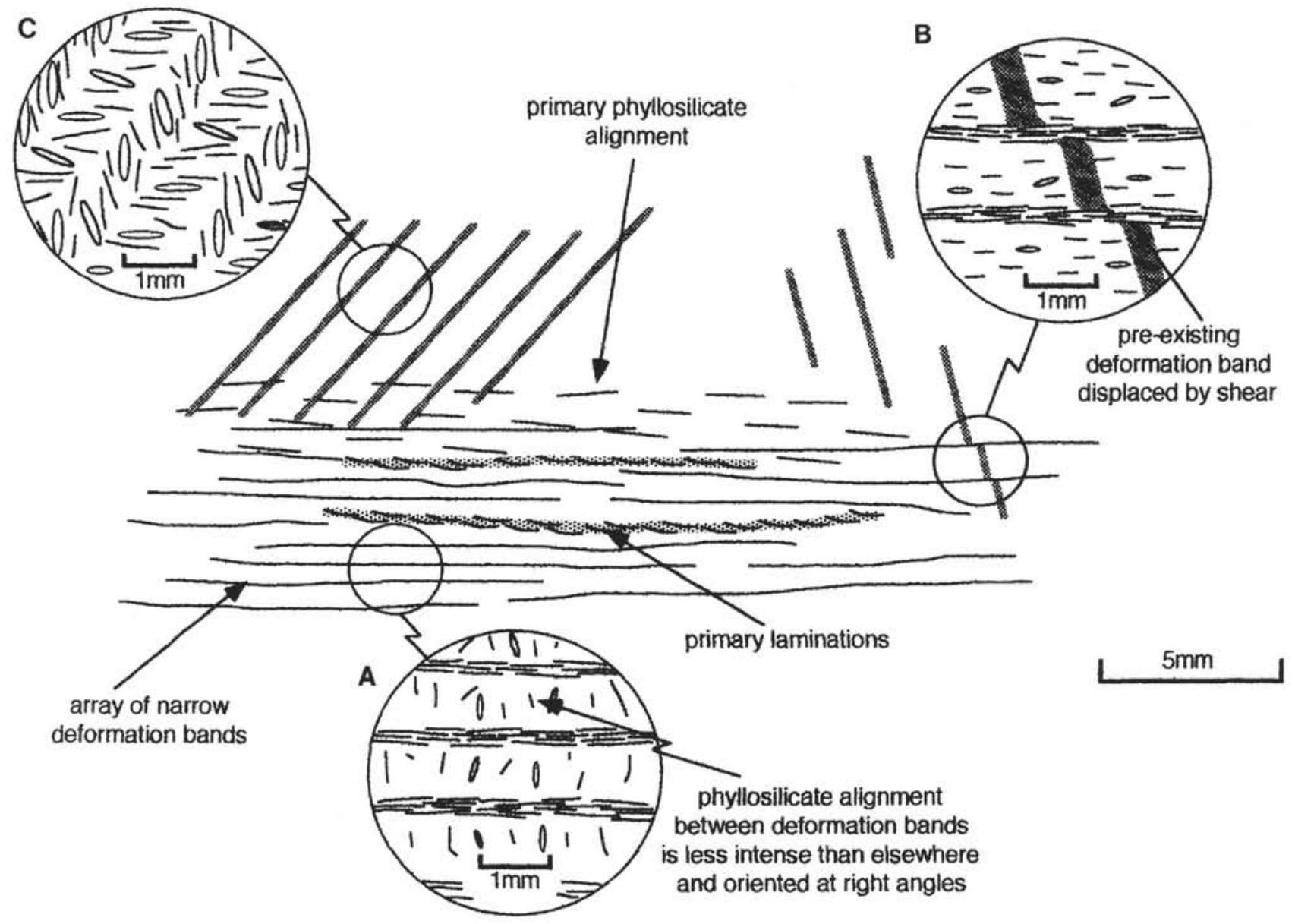

Figure 4. Sketch of microstructures, observed optically, associated with bedding-parallel deformation bands (A, B) and neighboring kink like structures (C). Such structures are restricted to the shallow sections of the thrust stack domain at Site 860. These may be associated with shearing along the limbs of the isoclinal slump-folds that are seen in these shallow sediments. The high-angle fabric in these thus represents parts of fold closures.

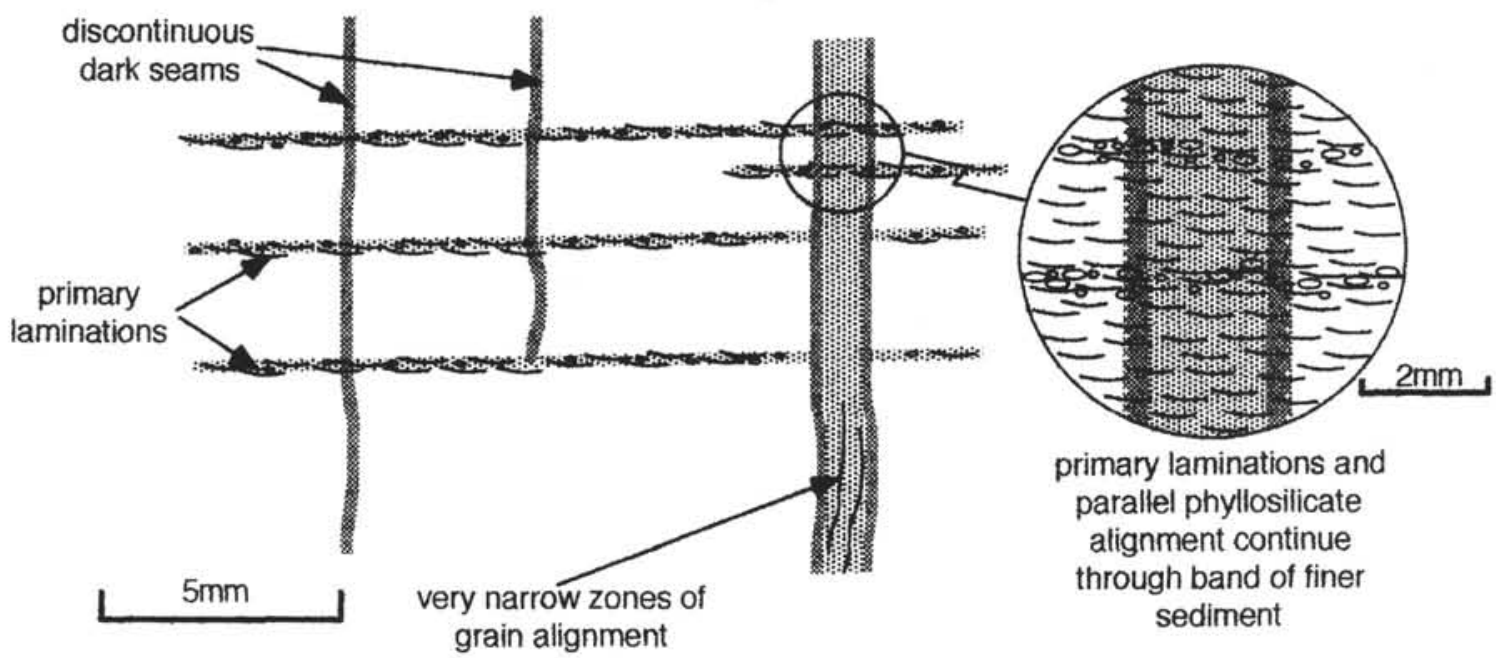

Figure 5. Sketch of microstructures associated with a broad deformation band at the base of the thrust stack domain. Optical observations indicate that there is no disruption of primary laminations within the band. 


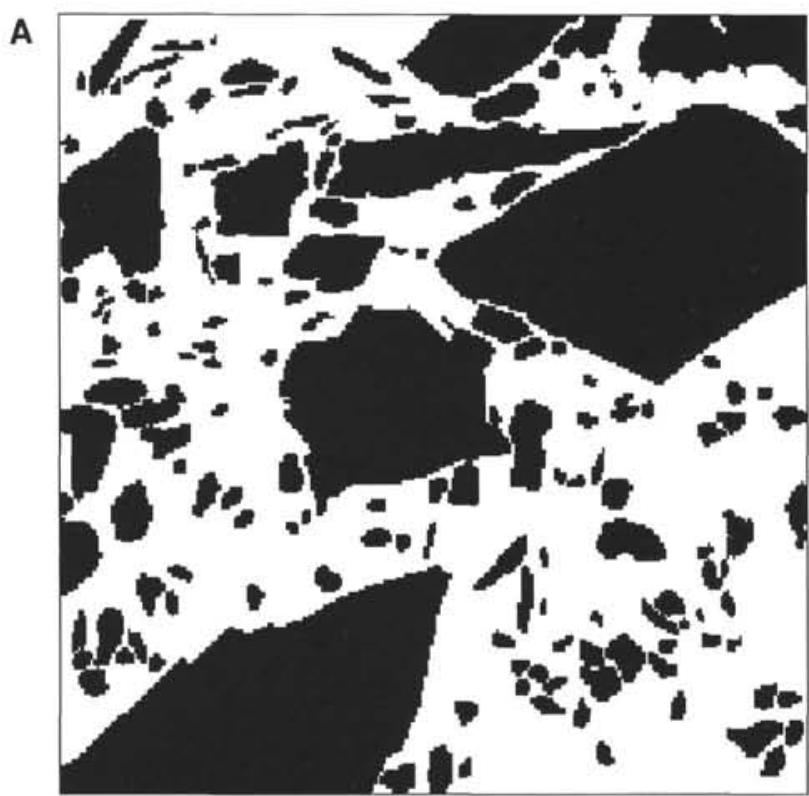

B

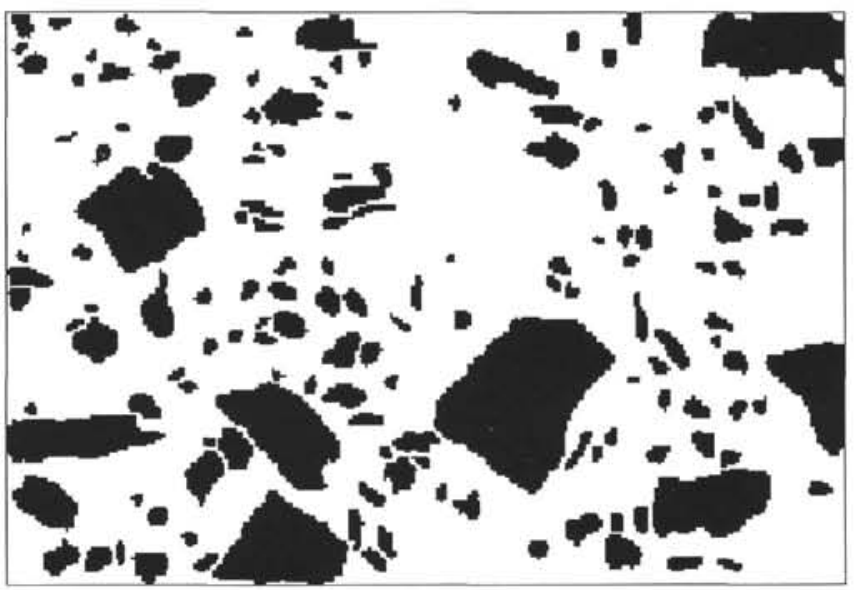

Figure 6. A. Image analysis diagram for outside deformation band shown in Plate 2, Figure 3. B. Image analysis diagram for inside deformation band shown in Plate 2, Figure 3.

\section{SPACE AND SHAPE FABRICS}

Characterization of the fabric of the deformation bands and the surrounding sediment is necessary to determine what they represent and the processes which formed them. Thus quantitative analysis of grain:matrix ratios, grain size, grain shape fabric, and grain spacing anisotropy has been completed across as many deformation bands as possible.

Plate 2, Figure 3, shows an example of an SEM photo-transect into a deformation band used for quantitative analysis. Digital images and statistical data were produced for samples from outside each deformation band (Fig. 6A) and inside each deformation band (Fig. 6B). Measurement of grains greater than approximately $50 \mathrm{~mm}$ and less than about $5 \mathrm{~mm}$ is difficult on BSE images which are of a suitable magnification to show the deformation bands. Thus large clasts and matrix clays could not be examined quantitatively. Since pore spaces within the samples are generally less than $5 \mathrm{~mm}$, it is not possible to measure actual porosity differences across the seams and porosity is included in calculations of matrix proportions. In total, five phototransects were examined, in three specimens. The results are shown in Table 1.

\section{Grain:matrix Ratios}

Grain ratios vary between $19.5 \%$ and $52.9 \%$ (Table 1). The grain ratios are far lower within four of the deformation bands (Numbers 1, 2,3 , and 5). In the fifth sample (Number 4), the grain ratio is slightly higher within the seam. This may be a different type of seam, or it may be a sampling error. In general, deformation bands appear to contain far more matrix material, though the composition of the matrix is the same as in the surrounding sediment.

\section{Grain Size}

Measurements of grain areas were manipulated to give the diameters of a circle of equivalent area. The calculated diameters were plotted on cumulative frequency diagrams. Plots of $\log _{10}$ grain diameters gave the best normal distributions. Thus, the geometric means were calculated for each data set together with the standard deviation of the log distribution at $50 \%$ confidence limits. Samples from outside the low porosity seams have consistently greater grain diameters than equivalent samples from inside (Table 1). Often the grains are three to four times as large outside as inside the low porosity seams, indicating that there has been either grain-size reduction within the seams, or injection of finer grained material along them.

\section{Grain Fabric}

Data on grain axial ratios and long-axis angles were analyzed using modified-Elliott Plots (Wheeler, 1984). This allows identification of any preferential orientation of grain shapes, which in turn may be related to strain.

Measurements of the orientation fabric, $R_{f}$ were obtained for each sample, where $R_{f}=1$ indicates no preferred orientation or strain. Observed $R_{f}$ values ranged between 1.026 and 1.418 (table 1), implying that only very low strains are preserved in the fabric. There is no consistent increase or decrease in fabric intensity within deformation bands. The angle of strain, $\Phi_{s}$, varies greatly between $-83.3^{\circ}$ and $+58.1^{\circ}$, with no consistent relationship of strain angle and samples inside or outside deformation bands. The "distribution spread invariant," $J$, is a measure of the spread of the axial ratios. Observed values of $J$ varied between 1.203 and 1.897 , which indicates that, once the effects of any strain are removed, the original grain fabrics differ from sample to sample.

\section{Grain Spacing Anisotropy}

Grain center spacing anisotropies have been analyzed using the Fry Plot method (Fry, 1979), developed for the Macintosh computer by DePaor (1989). If a set of grain spacings are not isotropic, there should be an elliptical hole in the center of the Fry plot. The magnitude and orientation of this ellipse indicates relative amount and direction of compaction in a sample, even though a grain orientation fabric may be absent.

Only two images showed any anisotropy: one from within a seam, the other from outside (Table 1). In both cases, the magnitude of the ellipse was small. This implies that there is no marked compaction either within or outside of deformation bands.

\section{THE ORIGIN AND SIGNIFICANCE OF DEFORMATION BANDS}

Although some of the deformation bands may be sedimentary structures such as lamination or cross-lamination, parallelism with other deformation bands and fractures suggests that they are deformation features. Also, hand specimen studies show that offset of features across deformation bands is common. Here we discuss the processes which could influence the development of deformation bands and use these as the basis for a discussion of the significance of deformation 
Table 1. Image analysis data comparing grain proportions, grain size, spacing anisotropy, and shape fabrics inside and outside of deformation bands.

\begin{tabular}{|c|c|c|c|c|c|c|c|c|c|c|c|}
\hline Number & $\begin{array}{l}\text { Depth } \\
\text { (mbsf) }\end{array}$ & $\begin{array}{c}\text { Specimen } \\
\text { (core, section, cm) }\end{array}$ & $\begin{array}{l}\text { Inside/ } \\
\text { outside }\end{array}$ & $\begin{array}{c}\text { Grain } \\
\%\end{array}$ & $\begin{array}{c}\text { Geometric } \\
\text { mean } \\
(\operatorname{diam} / \mu \mathrm{m})\end{array}$ & $\begin{array}{c}\mathrm{sd}+ \\
(\mu \mathrm{m})\end{array}$ & $\begin{array}{c}\text { sd- } \\
(\mu \mathrm{m})\end{array}$ & $\begin{array}{l}\text { Spacing } \\
\text { anisotropy }\end{array}$ & $R_{f}$ & $\begin{array}{l}\Phi \\
\left({ }^{\circ}\right)\end{array}$ & $J$ value \\
\hline \multirow[t]{2}{*}{1} & 553.74 & $64 X-4,54$ & In & 27 & 4.6 & 3.0 & 1.9 & No & 1.12 & -12 & 1.20 \\
\hline & & $64 \times-4.54$ & Out & 45 & 17.6 & 44.1 & 12.5 & No & 1.18 & 26 & 1.32 \\
\hline \multirow[t]{2}{*}{2} & 582.71 & $67 X-3,51$ & In & 24 & 2.9 & 2.0 & 1.2 & No & 1.28 & 31 & 1.46 \\
\hline & & $67 X-3,51$ & Out & 38 & 9.1 & 17.2 & 5.9 & No & 1.11 & 58 & 1.31 \\
\hline \multirow[t]{2}{*}{3} & 582.71 & $67 \times-3.51$ & In & 19 & 4.4 & 2.7 & 1.7 & Yes & 1.25 & 55 & 1.21 \\
\hline & & $67 \times-3,51$ & Out & 40 & 5.4 & 46 & 2.5 & No & 1.03 & -70 & 1.39 \\
\hline \multirow[t]{2}{*}{4} & 582.71 & $67 X-3,51$ & In & 31 & 2.0 & 1.2 & 0.7 & No & 1.13 & -39 & 1.28 \\
\hline & & $67 X-3,51$ & Out & 26 & 3.3 & 16 & 1.2 & No & 1.42 & -81 & 1.37 \\
\hline \multirow[t]{2}{*}{5} & 411.46 & $48 \times-5,42$ & In & 37 & 1.3 & 1.5 & 0.6 & No & 1,32 & 19 & 1.90 \\
\hline & & $48 X-5,42$ & Out & 53 & 7.4 & 7.1 & 3.8 & Yes & 1.20 & -51 & 1.24 \\
\hline
\end{tabular}

Note: Grain \% = proportion of grain area to matrix matrix area; geometric mean = geometric mean of grain diameters: sd+, sd- = positive and negative standard deviations of grain size distribution; $R_{f}=$ shape fabric magnitude (see text): $\left({ }^{\circ}\right)=$ shape fabric orientation; $I=$ spread of axial ratios once effect of strain has been removed.

bands. Some of the processes that we can infer are summarized in Figure 7.

\section{Processes Associated with the Development of Deformation Bands}

\section{Shearing}

There is considerable macroscopic and microscopic evidence for shear displacements associated with deformation bands.

\section{Injection of Entirely Foreign Lower Porosity Material}

Clear examples of sediment injection are observed. Grain:matrix ratios show that material in the deformation bands has a greater concentration of matrix material and a finer clast population. These data suggest that sediment injection may be an important process in the development of many deformation bands, including those with shear offsets. Quantitative parameters (Table 1) vary greatly between different deformation bands suggesting that, if there is injection of new material, it is not the same material along all deformation bands. Values of $J$ indicate that, once the effects of any strain are removed, the original grain fabrics differ from sample to sample. It is likely that injected vein material is of relatively local origin.

\section{Fracture and Precipitation from Fluid}

Fe-sulfide filled fractures can only be explained by precipitation of sulfide from crack filling fluids or physical/chemical transportation of precursor organic matter into the crack. Pyrite accumulation in the sediment beyond the crack tip have formed by the precipitation of pyrite forming material by fluids flowing along the crack and its process zone. The fact that shears disperse but do not deform the pyrite framboids suggests that the shearing occurred between the time that the pyrite forming material (organic matter) nucleated and the actual formation of the framboid structure. Shears may have nucleated on relatively weak organic rich horizons or alternatively fluid flow in shears may have enhanced their sulfide content. Given that sulfide-filled fractures must be explained by fluid flow it seems likely that the enhanced sulfide content within other deformation bands may also relate to fluids.

\section{Infilling of Porosity by Diagenetic Processes}

Some microtextures (Fig. 5) show that in-situ diagenetic alteration/precipitation has been an important process in the development of some deformation bands. The deformation bands appear to contain far more matrix material, although the composition of the matrix is the same as in the surrounding sediment. New matrix may have been precipitated with the same composition as the original matrix, and so lead to higher concentrations of matrix as a whole. Even so, this could probably not account for all of increase in matrix since the matrix volume within deformation bands is often larger than matrix together with porosity in the host sediment. If diagenetic alteration/precipitation has been an important process then the equivalence of grain and matrix compositions inside and out of deformation bands suggests that diagenesis within the deformation bands is not out of equilibrium with that in the host sediment and any differences are due to microcompositional zoning or, more likely, kinetic reasons.

\section{Grain-size Reduction}

Quantitative data and qualitative observations show that there are fewer grains and that grains are smaller inside deformation bands. Grain size reduction within shear zones is well documented (White et al., 1980). Grain size reduction can occur by cataclasis. However diagenetic breakdown of grain material, particularly unstable volcanic clasts and lapilli, is documented (Behrmann, Lewis, Musgrave, et al., 1992). It as likely that diagenetically weakened clasts would break down very easily during shear induced cataclasis. This would also account for the possible grain size reduction within the seams. It is also possible that chemical breakdown may have preferentially occurred along the seams due to localized/channelized fluid flow.

\section{Collapse of Porosity due to Deformational Compaction}

Grain-shape and grain-spacing fabrics imply that the material both inside and outside the low porosity seams is relatively unstrained, and there is no marked compaction either within the host sediment, or across the seams. Thus, the seams are not primarily compaction features.

Having said this there is significant grain alignment in some of the deformation bands and localized grain fabrics, at deformation band margins for instance, are relatively common. However these fabrics must have developed in the absence of bulk compaction within deformation bands. The most likely mechanism for development of grain fabrics, particularly at deformation band margins, is by rotation of grains during active fluid flow.

\section{Dilation, Shear, and Fluid Flow}

Many of the processes inferred from microtextural observations point towards the importance of fluids and fluid flow in the generation of deformation bands. Development of deformation bands must be intimately associated with fluid flow although diagenesis must continue after the development of the bands to allow growth of framboidal Fe-sulfide.

Many deformation bands show shear offsets, indicating that deformation is the underlying driving force in their development. However, the patterns of alignment, the injection of foreign material and chemical changes within the deformation bands can only be explained by the association of fluid flow with the deformation. Moreover, generation of deformation bands of lower porosity than the host sediment requires 


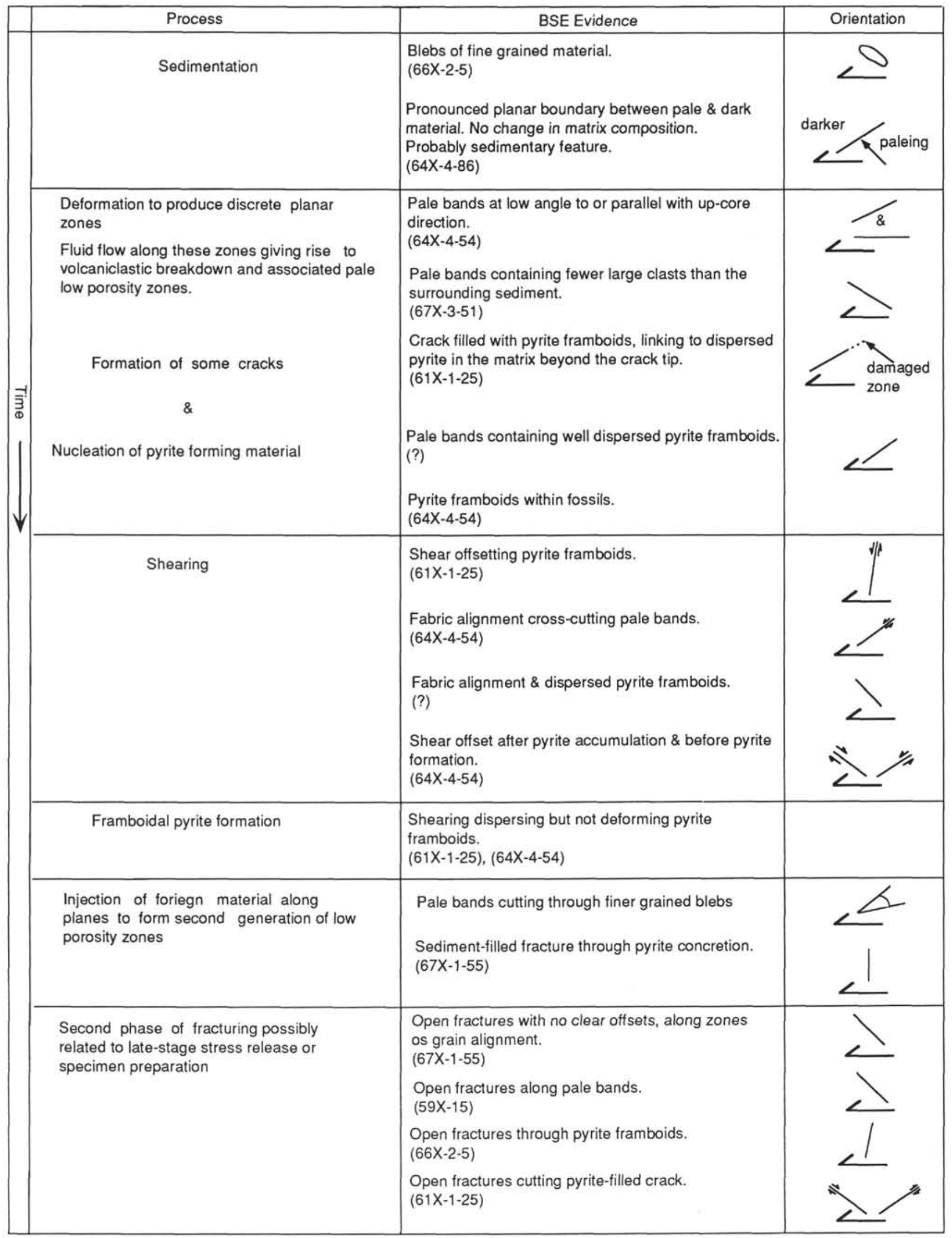

Figure 7. Summary of processes and orientations set within a time frame for the broken formation of Site 860 . 
that a process of dilation and collapse is important. It is likely that deformation bands relate to fluid pressure pulses allowing transient dilation, shear and injection of foreign material. During this process, diagenetically weakened clasts are broken down facilitating grainsize reduction. Collapse of the structure following a drop in fluid pressure creates local grain alignment fabrics and dumping of the matrix rich material carried by the fluid accounts for significant porosity reduction. Whether an individual deformation band represents a single flow event or is the result of more than one successive pulse is unclear. The variety of processes and geometries of observed deformation bands reflects wide lithological variation together with variable timing, duration and rates of fluid pressure change.

\section{ACKNOWLEDGMENTS}

Specimen preparation was carried out by Dave Oates at the British Geological Survey. Geoff Lloyd provided invaluable advice on SEM work. Samples were available through the international Ocean Drilling Program and the research was funded through NERC grant GST/02/682.

\section{REFERENCES ${ }^{*}$}

Agar, S.M., Prior, D.J., and Behrmann, J.H., 1989. Back-scattered electron imagery of the tectonic fabrics of some fine-grained sediments: implications for fabric nomenclature and deformation processes. Geology, 17:901-904.

Bangs, N., Cande, S.C., Lewis, S.D., and Miller, J., 1992. Structural framework of the Chile Margin at the Chile Ridge collision zone. In Behrmann, J.H., Lewis, S.D., Musgrave, R.J., et al., Proc. ODP, Init. Repts., 141: College Station, TX (Ocean Drilling Program), 11-21.

Behrmann, J.H., Lewis, S.D., Musgrave, R.J., et al., 1992. Proc. ODP, Init. Repts., 141: College Station, TX (Ocean Drilling Program).

Bray, C.J., and Karig, D.E., 1985. Porosity of sediments in accretionary prisms, and some implications for dewatering processes. J. Geophys. Res., 90:768-778.

Byrne, T., Maltman, A., Stephenson, E., Soh, W., and Knipe, R., 1993. Deformation structures and fluid flow in the toe region of the Nankai accretionary prism. In Hill, I.A., Taira, A., Firth, J.V., et al., Proc. ODP Sci. Results, 131: College Station, TX (Ocean Drilling Program), 83-101.

Cande, S.C., and Leslie, R.B., 1986. Late Cenozoic tectonics of the southern Chile Trench. J. Geophys. Res., 91:471-496.
DePaor, D., 1989. An interactive program for doing Fry strain analysis on the Macintosh microcomputer. J. Geol. Educ., 37:171-180.

Fry, N., 1979. Density distribution techniques and strained length methods for determination of finite strains. J. Struct. Geol., 1:221-229.

Knipe, R.J., Agar, S.M., and Prior, D.J., 1991. The microstructural evolution of fluid flow paths in semi-lithified sediments from subduction complexes. Philos. Trans. R. Soc. London A, 335:261-273.

Lloyd, G.E., 1985. Review of instrumentation, techniques and applications of SEM in mineralogy. In White, J.C. (Ed.), Applications of Electron Microscopy in Earth Sciences. Short Course-Mineral. Assoc. Can., 11:155-188.

Maltman, A.J., Byrne, T., Karig, D., and Lallement, S., 1992. Structural geological evidence from ODP Leg 131 regarding fluid flow in the Nankai prism, Japan. Earth Planet. Sci. Lett., 109:463-468.

Maltman, A.J., Byrne, T., Karig, D.E., Lallemant, S., Knipe, R., and Prior, D., 1993. Deformation structures at Site 808, Nankai accretionary prism, Japan. In Hill, I.A., Taira, A., Firth, J.V., et al., Proc. ODP, Sci. Results, 131: College Station, TX (Ocean Drilling Program), 123-133.

Moore, J.C., Brown, K.M., Horath, F., Cochrane, G., MacKay, M., and Moore, G., 1991. Plumbing accretionary prisms: effects of permeability variations. Philos. Trans. R. Soc. London A, 335:275-288.

Moore, J.C., Mascle, A., Taylor, E., Andreieff, P., Alvarez, F., Barnes, R., Beck, C., Behrmann, J., Blanc, G., Brown, K., Clark, M., Dolan, J.F., Fisher, A., Gieskes, J., Hounslow, M., McLellan, P., Moran, K., Ogawa, Y., Sakai, T., Schoonmaker, J., Vrolijk, P., Wilkens, R.H., and Williams, C., 1988. Tectonics and hydrogeology of the northern Barbados Ridge: results from Ocean Drilling Program Leg 110. Geol. Soc. Am. Bull., 100:1578-1593.

Prior, D.J., and Behrmann, J.H., 1990. Thrust-related mudstone fabrics from the Barbados forearc: a backscattered scanning electron microscope study. J. Geophys. Res., 95:9055-9067.

Wheeler, J., 1984. A new plot to display the strain of elliptical markers. $J$. Struct. Geol., 6:417-423.

White, S.H., Burrows, S.E., Carreras, J., Shaw, N.D., and Humphreys, F.J. 1980. On mylonites in ductile shear zones. J. Struct. Geol., 2:175-187.

\footnotetext{
- Abbreviations for names of organizations and publications in ODP reference lists follow the style given in Chemical Abstracts Service Source Index (published by American Chemical Society).
}

Date of initial receipt: 19 July 1993

Date of acceptance: 4 October 1994

Ms 141SR-017 

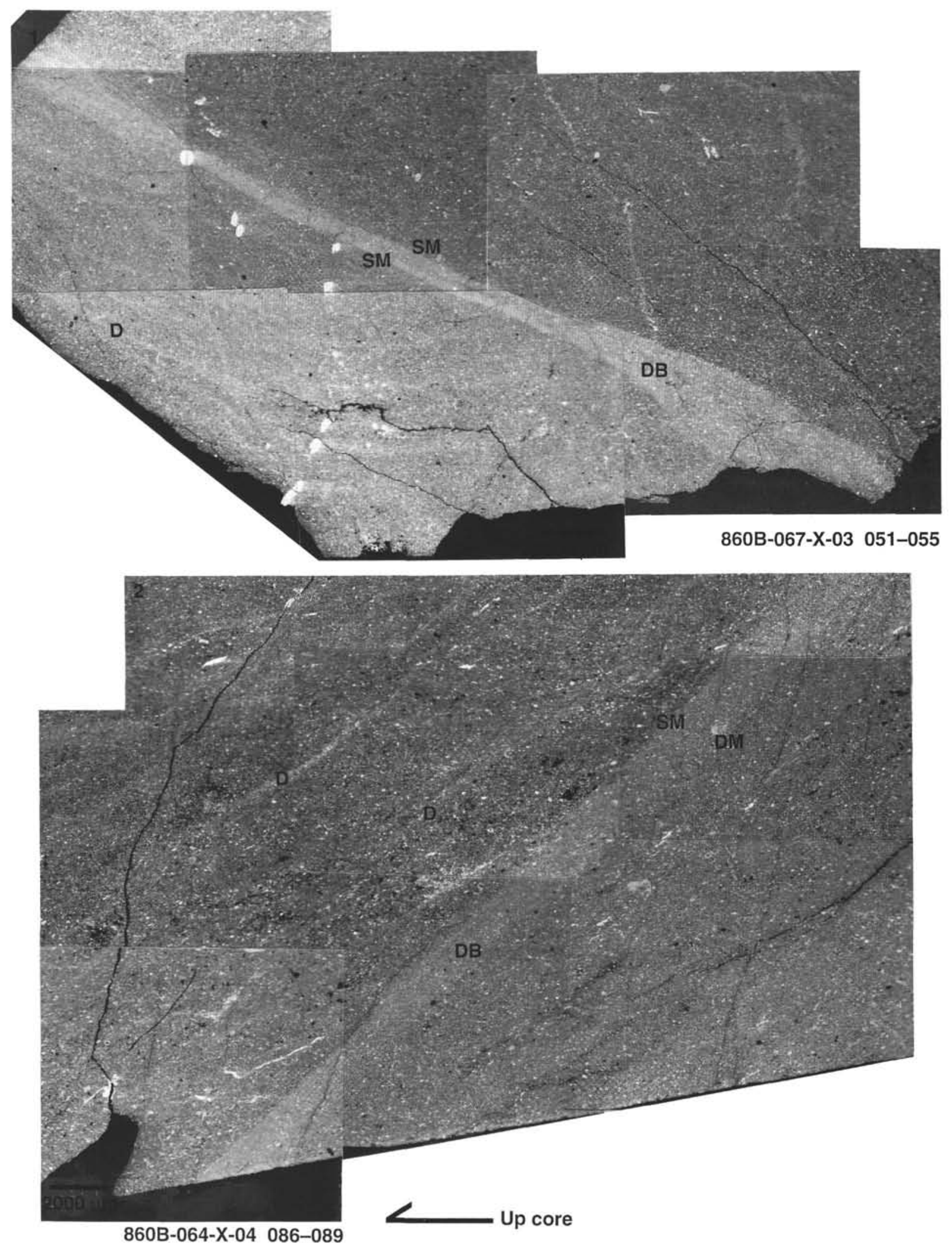

Plate 1. 1. A wide deformation band (DB) characterized by brighter backscatter intensity. Both margins of the band are sharp (SM), and parallel to other deformation bands (e.g., D). 582 mbsf. 2. A wide DB with one SM and one diffuse margin (DM), parallel to many smaller deformation bands (D). Porosity in the host sediment is highly variable. $555 \mathrm{mbsf}$. 

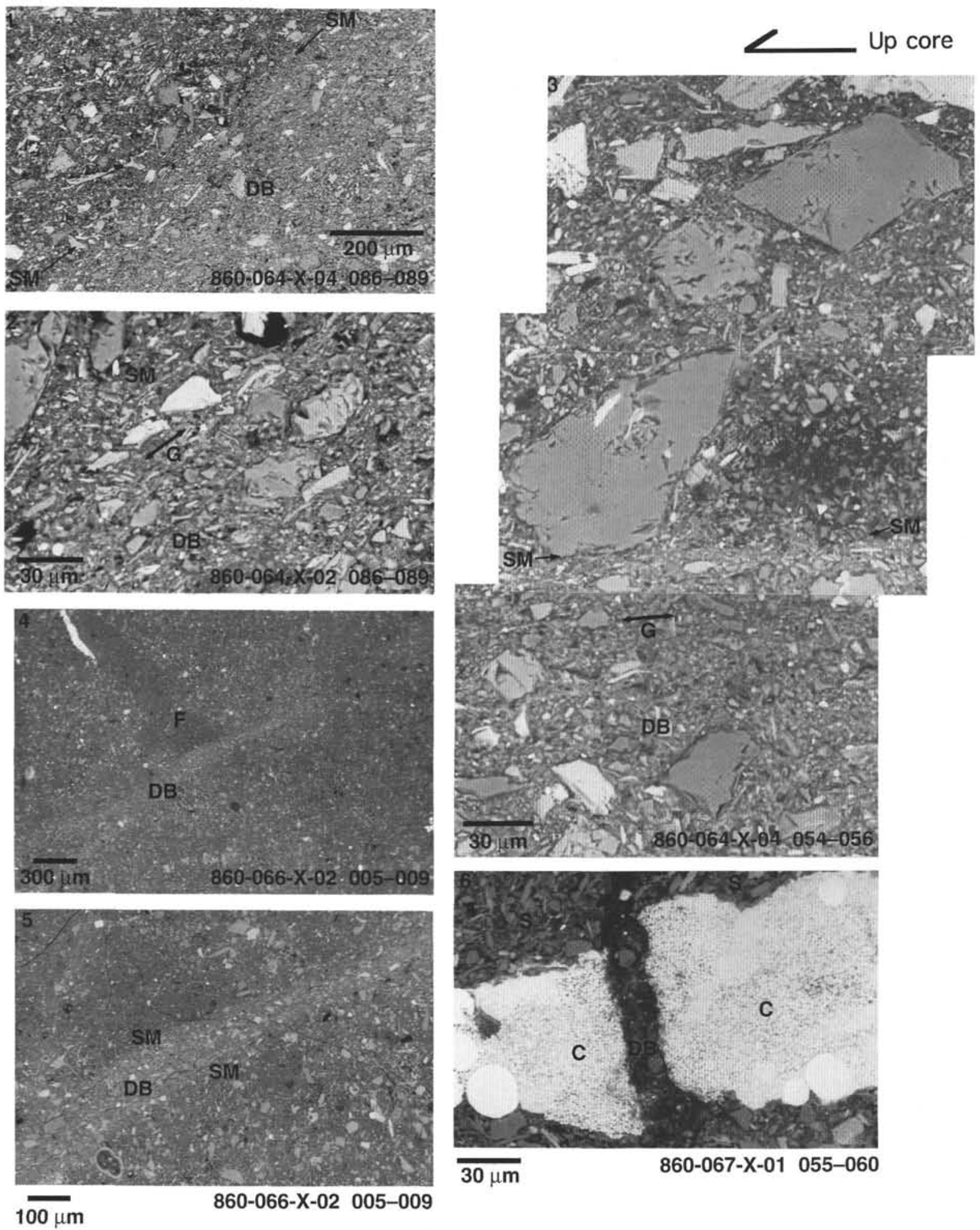

$\overline{30 \mu \mathrm{m}}$

$860-067-X-01 \quad 055-060$

Plate 2. 1. A sharp deformation band margin (SM). Reduced porosity within the deformation band (DB) produces brighter backscatter intensity. 555 mbsf. 2. Close-up of 1 showing grain alignment $(\mathrm{G})$ parallel to the sharp margin (SM) of the deformation band (DB). 3. Grain alignmen (G) concentrated along a sharp deformation band margin (SM). There is marked reduction of porosity within the deformation band (DB). 555 mbsf. 4. A coarse grained deformation band (DB) cutting a fine grained clast (F), 571 mbsf. 5. Close-up of 4. Both margins of the band (SM) are sharp and porosity is uniform across the deformation band (DB). 6. A deformation band (DB) consisting of a sediment-filled fracture through an Fe-sulfide concretion (C). Sediment within the fracture contains fewer large clasts and images slightly darker than the surrounding sediment (S). 580 mbsf. 


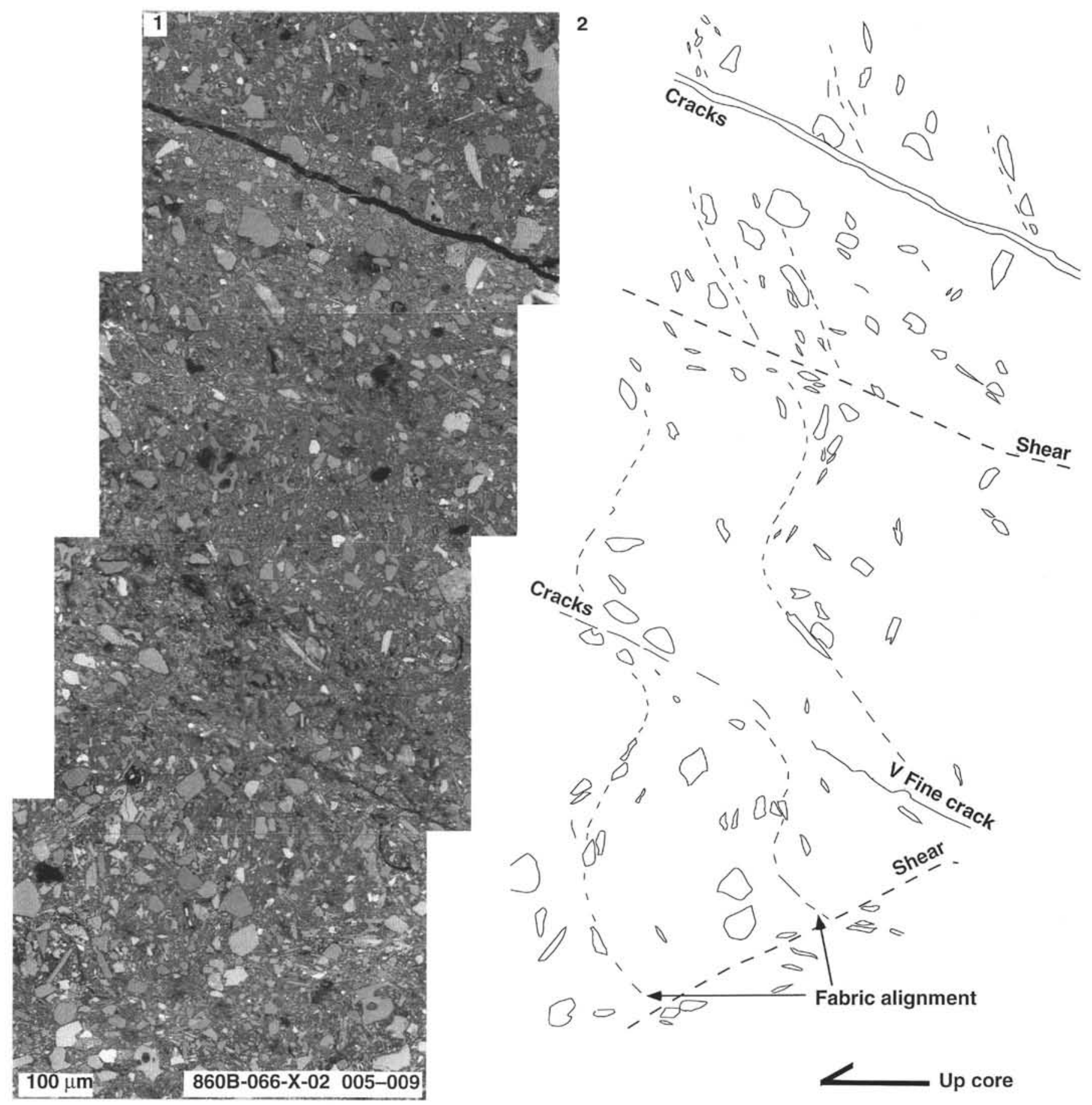

Plate 3. 1. A complex network of deformation bands with variable porosity and fabric development. $571 \mathrm{mbsf}$. 2. Annotated sketch of $\mathbf{1}$ 

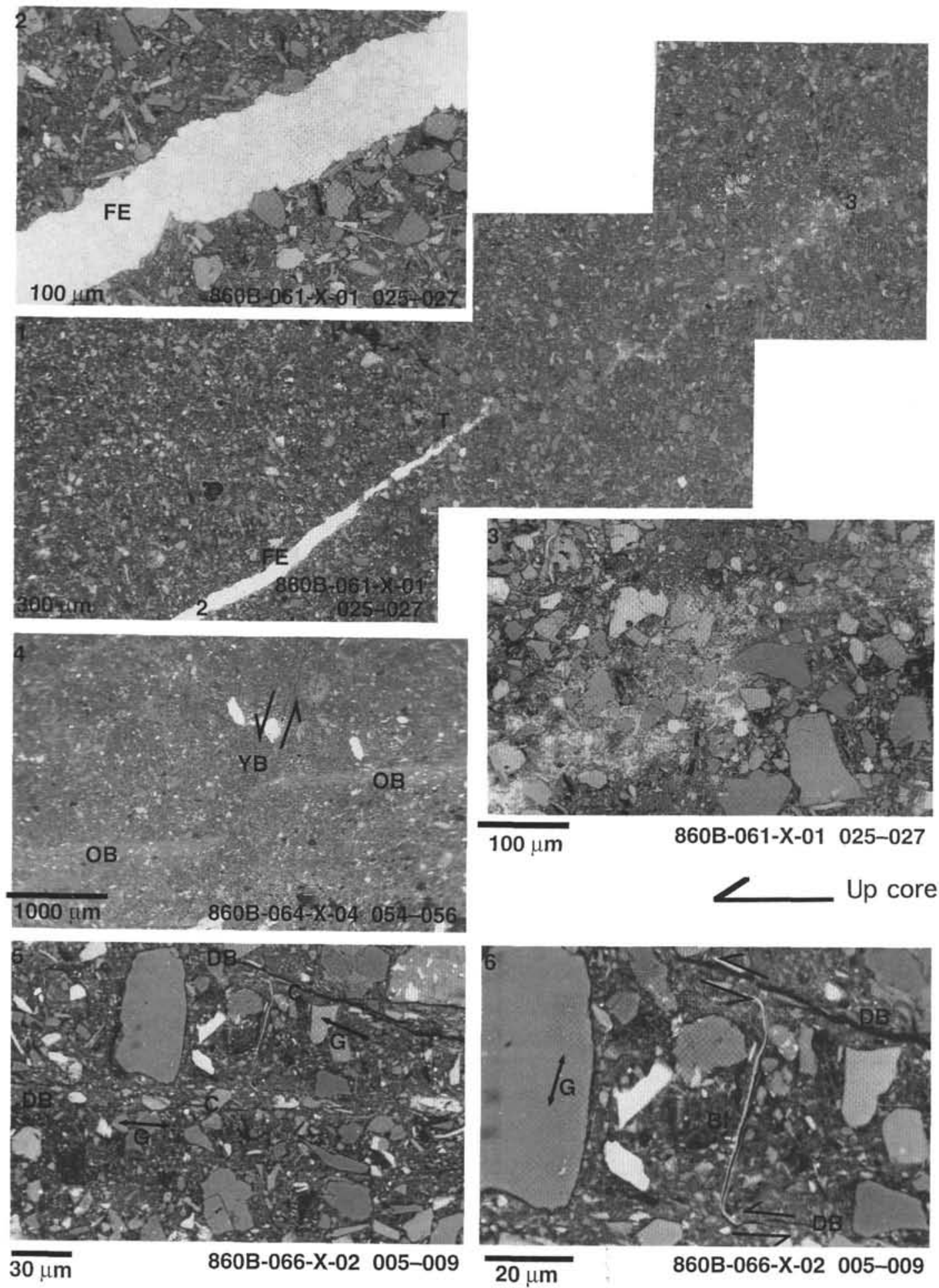

$\overline{30 \mu \mathrm{m}}$

860B-066-X-02 005-009

$20 \mu \mathrm{m}$

Plate 4. 1. An Fe-sulfide-filled crack (FE). Beyond the crack tip ( $\mathrm{T}$ ) there is a concentration of Fe-sulfide in the matrix. Close-ups 2 and 3 are located on this figure. 572 mbsf. 2. Close-up of 1. Framboidal texture of the Fe-sulfide (FE) is well developed within the crack. Position located on 1. 3. Close-up of 1. As in many deformation bands, there is a concentration of small Fe-sulfide framboids within the matrix. Position located on 1. 4. A younger deformation band (YB) offsetting an older deformation band (OB). Arrows indicate sense of offset. $555 \mathrm{mbsf}$. 5. Two deformation bands (DB) at an angle to each other. Some grain alignment (G) of smaller clasts is developed and cracks (C) are preferentially located within the bands. 571 mbsf. 6. Close up of 5. A biotite clast (BI), aligned in an earlier grain fabric (G), is deflected into the deformation bands (DB). Arrows indicate sense of shear interpretable from the deflections. 


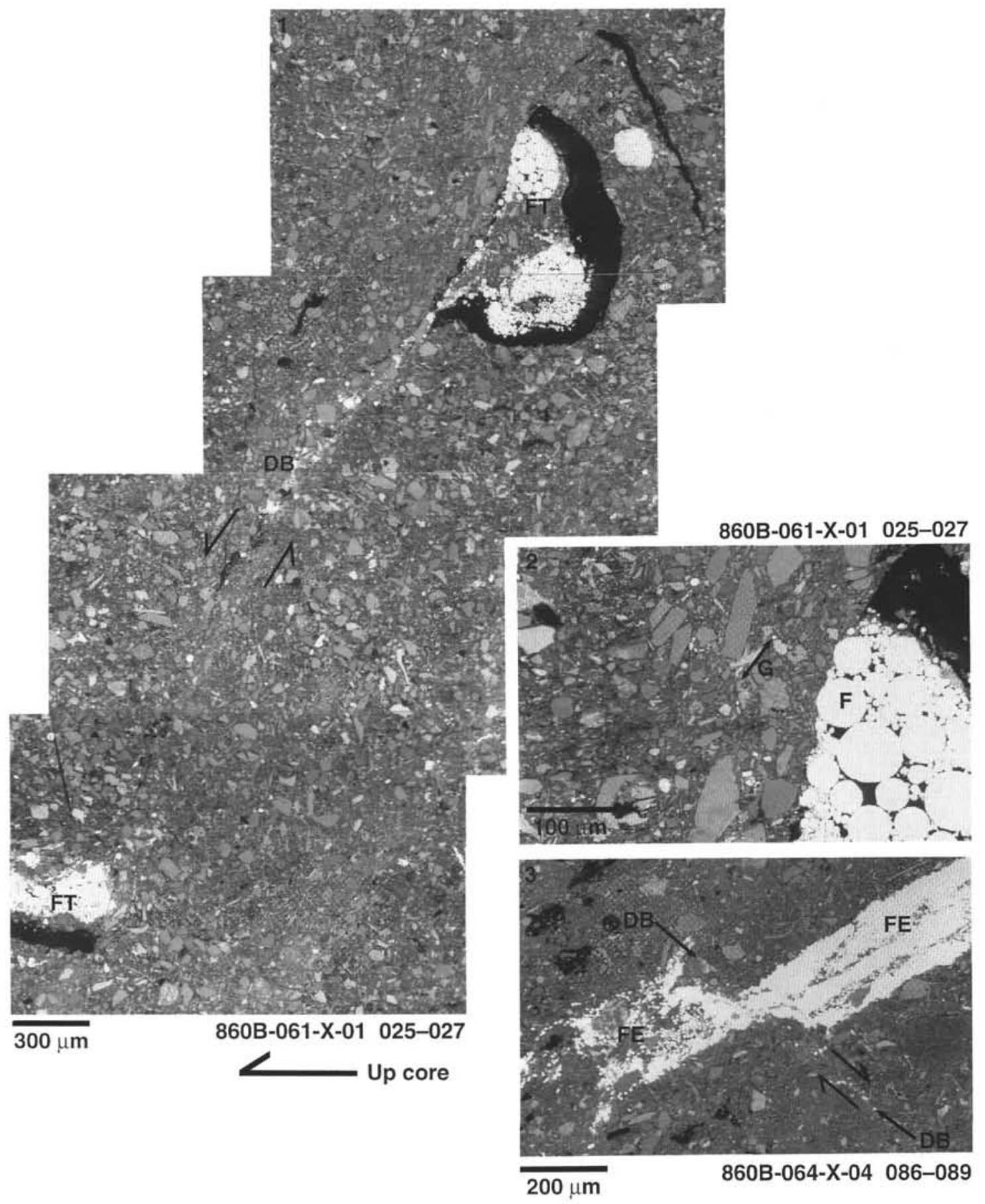

Plate 5. 1. An Fe-sulfide-filled with fossil test (FT) offset by a deformation band (DB). There is a concentration of Fe-sulfide in the deformation band matrix along the offset. Arrows indicate sense of offset. $522 \mathrm{mbsf}$. 2. Close up of the upper fossil test in 5a. Individual Fe-sulfide framboids $(\mathrm{F})$ are not deformed, although grain alignment $(\mathrm{G})$ is developed within the deformation band. 3 . Fe-sulfide marker (FE) offset by a deformation band (DB). Again, the Fe-sulfide framboids are undeformed. Arrows indicate sense of offset. 555 mbsf. 